\title{
ORIGINAL ARTICLE Genetic connectivity and diversity in inselberg populations of Acacia woodmaniorum, a rare endemic of the Yilgarn Craton banded iron formations
}

\author{
MA Millar, DJ Coates and M Byrne \\ Historically rare plant species with disjunct population distributions and small population sizes might be expected to show \\ significant genetic structure and low levels of genetic diversity because of the effects of inbreeding and genetic drift. Across the \\ globe, terrestrial inselbergs are habitat for rich, often rare and endemic flora and are valuable systems for investigating \\ evolutionary processes that shape patterns of genetic structure and levels of genetic diversity at the landscape scale. We \\ assessed genetic structure and levels of genetic diversity across the range of the historically rare inselberg endemic Acacia \\ woodmaniorum. Phylogeographic and genetic structure indicates that connectivity is not sufficient to produce a panmictic \\ population across the limited geographic range of the species. However, historical levels of gene flow are sufficient to maintain \\ a high degree of adaptive connectivity across the landscape. Genetic diversity indicates gene flow is sufficient to largely \\ counteract any negative genetic effects of inbreeding and random genetic drift in even the most disjunct or smallest \\ populations. Phylogeographic and genetic structure, a signal of isolation by distance and a lack of evidence of recent genetic \\ bottlenecks suggest long-term stability of contemporary population distributions and population sizes. There is some evidence \\ that genetic connectivity among disjunct outcrops may be facilitated by the occasional long distance dispersal of Acacia \\ polyads carried by insect pollinators moved by prevailing winds. \\ Heredity (2013) 111, 437-444; doi:10.1038/hdy.2013.66; published online 17 July 2013
}

Keywords: gene flow; inselberg; isolation; landscape; phylogeographic structure

\section{INTRODUCTION}

For plant species, demographic and genetic connectivity is affected by seed and pollen dispersal vectors, by a number of life history traits including life form, longevity and the mating system, and by the size and spatial arrangement of populations. Rare plant species and those with specific habitat requirements often have geographically disjunct and small population sizes. For these species, the surrounding landscape typically comprises a matrix of unsuitable habitat that acts as an effective physical barrier to dispersal and the size and spatial arrangement of populations assumes an important role in the structuring and maintenance of genetic diversity. Limitations to connectivity result in a degree of demographic isolation and genetic isolation among populations (Slatkin, 1987), and produce the phylogeographic and genetic structuring observed in many habitat specific, rare, endemics (Yates et al., 2007; Byrne and Hopper, 2008; Butcher et al., 2009). Limited connectivity among disjunct populations can result in reduced levels of genetic diversity as a result of increased levels of inbreeding and via the negative impacts of genetic drift (Slatkin, 1987; Ellstrand, 1992), both of which are further enhanced in small populations. Structuring and maintenance of genetic diversity has a key role in the ultimate persistence of species as they evolve and adapt to changing conditions. As a result of this, knowledge of the effects of genetic connectivity is central to understanding the evolution of natural systems and for informing the fields of population biology and conservation genetics (Lowe and Allendorf, 2010).
Very small amounts of gene flow, less than one migrant per generation, are required to spread advantageous alleles among populations over long periods of evolutionary time, producing the 'adaptive connectivity' (Lowe and Allendorf, 2010) that maintains cohesiveness at the species level (Rieseberg and Burke, 2001). It is also expected, under an island model of migration, that very small amounts of migration will be sufficient to reduce the negative genetic effects of inbreeding (inbreeding connectivity) and avoid the negative effects of genetic drift (Wright, 1951; Lowe and Allendorf, 2010). This degree of connectivity is required to ensure that genetic diversity and adaptive potential of disjunct or small populations are maintained. In this case, genetic structure or differentiation resulting from allele frequency divergence among populations, because of genetic drift, may still be observed. Higher levels of genetic connectivity, in the order of $>10$ migrants per generation, are likely to be required to provide 'drift connectivity' (Lowe and Allendorf, 2010) and produce identical allele frequencies in all populations, or a totally panmictic population structure.

The flora of the Mediterranean ecosystem of south west Western Australia (WA) is endowed with a large number of habitat specific, endemic species (Myers et al., 2000), many of which have geographically restricted disjunct population distributions and small population sizes (Coates, 2000). A number of studies have described high levels of genetic structuring among populations of these species (Coates, 2000; Yates et al., 2007; Byrne and Hopper, 2008; Millar and 
Byrne, 2013). Historical rarity, geographic restriction, disjunct population distributions and genetic structuring in the WA flora is thought to be largely the result of a diverse mosaic of soils (Anand and Paine, 2002), localised stochastic extinction events driven by climatic fluctuations, an overall increasing aridity of the environment during the Pleistocene, and the actions of fire across the landscape over long time frames (Hopper, 2009).

The Yilgarn Craton forms the bulk of the WA landmass and has been largely stable in terms of mountain formation, inundation and glaciation for 250 million years (Anand and Paine, 2002). Continual weathering over this time has exposed banded ironstone formations (BIFs) extending north and east into the semi-arid and arid areas (Gibson and Yates, 2010). These small rock outcrops are now the dominant natural features of the otherwise flat landscape. Cracks and crevices in BIFs concentrate rainfall and runoff and provide a mesic winter wet microhabitat for a rich range of highly habitat-specific plant species, many of which are inselberg restricted endemics (Hopper et al., 1996). As well as being of considerable antiquity, inselbergs are also some of the few ecosystems worldwide that remain largely unaffected by human disturbance (Porembski, 2007). Terrestrial inselbergs also typically vary in size and degree of spatial disjunction and, compared with other specialised terrestrial habitats, this makes them ideal model systems for investigating the impacts of evolutionary processes such as gene flow that shape patterns of genetic structure and levels of genetic diversity at the landscape scale (Porembski and Barthlott, 2000).

This study aimed to test a number of hypotheses regarding the impacts of historical rarity, habitat specificity and population isolation and size on genetic connectivity via migration for Acacia woodmaniorum (Maslin and Buscumb, 2007), an endemic species of the ancient BIFs of south west WA. As a result of its limited distribution, we were able to comprehensively investigate patterns of genetic structure and levels of genetic diversity across the entire range of this species. Specifically, we aimed to address the hypotheses that (i) significant genetic structure, involving geographically disjunct populations on historically disjunct BIF outcrops, will be a feature of this species and (ii) levels of genetic diversity will be low in A. woodmaniorum, with lower diversity in more disjunct or smaller populations as a result of limited genetic connectivity. We also aimed to determine the effects of geographic distance, disjunction and size of the specialised inselberg habitat on levels and patterns of migration and genetic connectivity.

\section{MATERIALS AND METHODS}

\section{Study species and landscape}

A. woodmaniorum is a recently described sprawling prickly shrub (Maslin and Buscumb, 2007). Plants are highly substrate specific for the skeletal soils, steep slopes, rock crevices and gullies of a series of low BIF outcrops. Little is known of the species biology or ecology. Seed and pollen dispersal mechanisms in A. woodmaniorum have not been studied, although the off-white aril suggests seed is likely to be dispersed largely by ants, as is common for Australian arid zone Acacia (Davidson and Morton, 1984; Gómez and Espadaler, 1998). Pollen dispersal is assumed to be largely by generalist insects including moths, wasps, beetles and bees (Stone et al., 2003). The species has an extremely restricted distribution covering an area of $<40 \mathrm{~km}^{2}$ and extending a maximum linear distance of a little over $8 \mathrm{~km}$. Approximately 25000 plants are known.

The study area is located on the north east margin of the biologically diverse mesic South West Botanical Province and is a floristically rich transitional zone between the South West Botanical Province and the arid Eremaean Botanical Province (Beard, 1976; Hopper and Gioia, 2004). This area has a semi-desert Mediterranean climate with annual rainfall of $300-400 \mathrm{~mm}$ that occurs mostly during winter (Beard, 1976; Markey and Dillon, 2008). Summer rainfall events can be significant and are typically thunderstorms and heavy downpours from tropical cyclone remnants (Markey and Dillon, 2008). Off the BIF ranges, the surrounding clay, silt and sand plains are dominated by a low Mulga (Acacia aneura) woodland with other Acacia, Allocasuarina, Melaleuca and Eucalyptus species, and Senna, Eremophila and Acacia shrubs on low hills (Beard, 1976)

Populations of A. woodmaniorum can be separated into four main geological and geographical regions. Habitat is relatively continuous across the main range on Mungada/Windaning Ridge and this is where the majority of the plants occur (Figure 1). The section of Mungada/Windaning Ridge orientated east/west is called Mungada Ridge and the section of Mungada/Windaning Ridge orientated north/south is called Windaning Ridge. Several small populations occur on ironstone breakaways off this main range. The Jasper Hill region is $6 \mathrm{~km}$ north of the Mungada/Windaning Ridge and is comprised of a number of smaller, discrete BIF ridges separated by habitat unsuitable for A. woodmaniorum. Populations in this region range in size from tens of plants to just over 1000 plants. Populations also occur on the named BIF formations Terapod and Blue Hill. The number of plants present and the number sampled from each site are provided (Supplementary Table S1). Small areas of the western end of Mungada/Windaning Ridge and the Blue Hill site are highly disturbed as a result of previous mineral extraction in the 1960s and 1970s.

\section{Sample collection and genotyping}

Phyllodes were collected from 573 plants covering a total of 33 sample sites (populations) with sampling covering the species range and providing a broad range of geographical distances among sample sites (Figure 1, Supplementary Table S1). The position of all sampled plants was recorded using a differential Global Positioning Satellite. Mapping and determination of the linear geographic distance between the given population and the next nearest population (population isolation) for 24 disjunct, relatively small populations (that is, not including sampling sites located across the large population on Mungada/Windaning Ridge, MA1-6 and WA1-3) was conducted using Geographical Information Software (GIS, Arcmap 9.1, Esri Australia, Brisbane, QLD, Australia; Figure 1, Supplementary Table S1).

Phyllode samples were lyophilised, DNA extracted and all plants genotyped using 15 nuclear microsatellite primer pairs (Aw012, Aw124, Aw129, AwB001, AwB003, AwB008, AwB009, AwB107, AwB108, AwB109, AwC001, AwD008, AwD010, AwD012 and AwD116) developed for A. woodmaniorum (Millar, 2009).

\section{Data analysis}

Utility of loci. Individual loci were tested for departure from Hardy-Weinberg equilibrium and locus pairs tested for linkage disequilibrium at each sample site using exact tests as implemented in the program GENEPOP version 4.0 (Raymond and Rousset, 1995). Sequential Bonferroni corrections were applied to correct for multiple comparisons. Presence and frequency of null alleles were assessed using the maximum likelihood expectation maximisation algorithm implemented in GENEPOP.

Genetic diversity. Genetic diversity parameters were assessed for each sample site, each of four geological regions, each of the genetic clusters detected in the structural analysis and for the species overall using the GenAlEx version 6.3 program (Peakall and Smouse, 2006). Levels of genetic diversity were hierarchically partitioned using the analysis of molecular variance method implemented in GenAlEx conducted on $F_{S T}$ values at the individual, population and regional level, with statistical testing conducted using 999 random permutations. To account for the effect of variable population sizes, rarefaction was used to estimate the mean number of alleles per locus (allelic richness $\left.A_{\mathrm{r}}\right)$ and the mean number of private alleles per locus $\left(P_{\mathrm{r}}\right)$ using the program HP-RARE 1.0 (Kalinowski, 2005). The relationships among both population isolation and size, and allelic richness and the number of private alleles, were investigated using linear regression.

We tested for founder effects or genetic bottlenecks using the BOTTLENECK version 1.2.0.2 program (Piry et al., 1999). Equilibrium conditions were simulated for all sites at which $>15$ plants were sampled (the analysis is not suitable for smaller populations because of type 1 error rates) using 1000 replications assuming a two-phased model of mutation with 90\% stepwise mutation, as recommended by the author (Piry et al., 1999) for microsatellite 


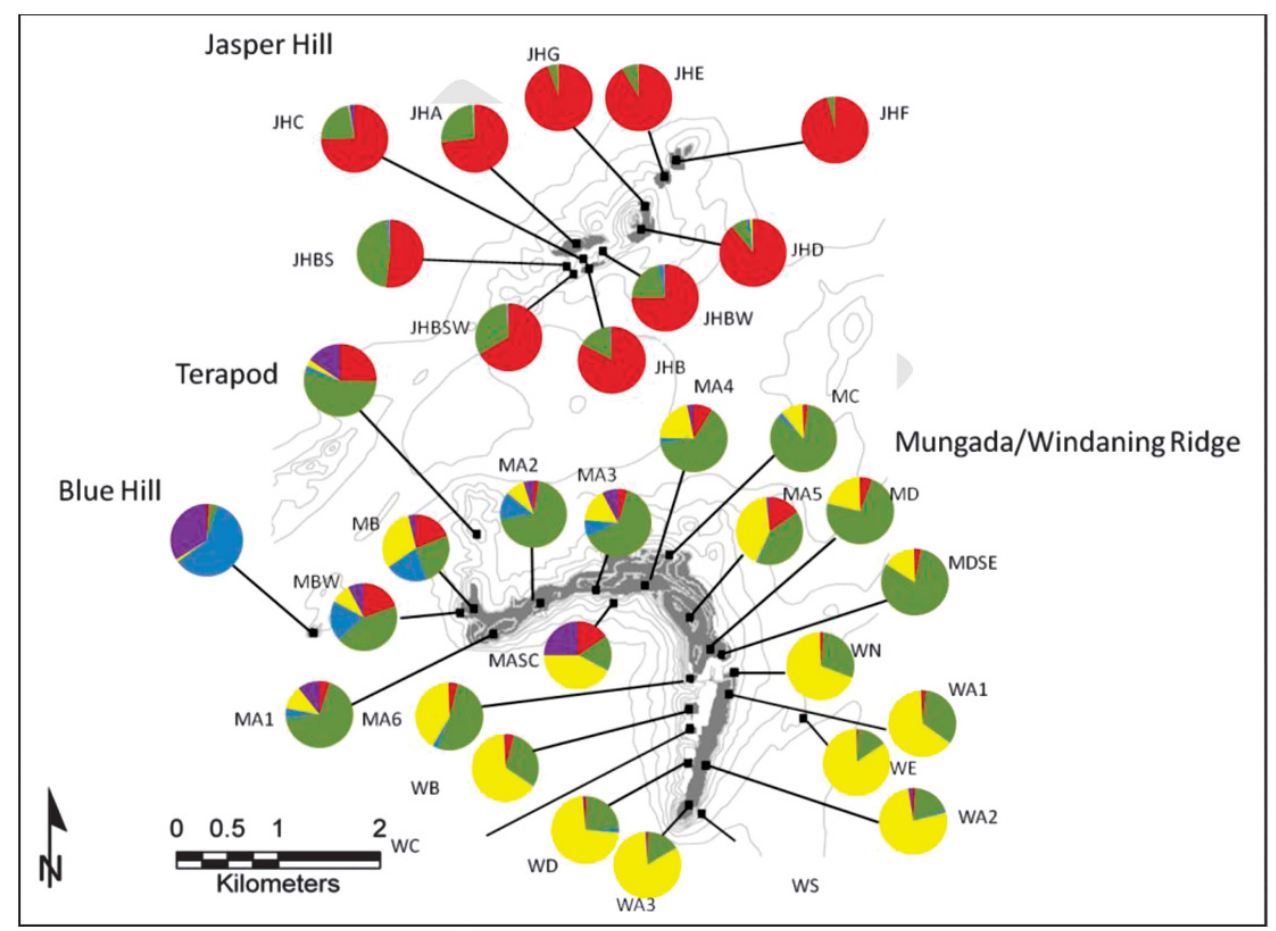

Figure 1 Map of the distribution (grey shade) and sample sites (black squares) of $A$. woodmaniorum. Sample site and region names correspond to those in Supplementary Table S1. Pie charts indicate the proportion of assignment of sampled populations to each of five genetic clusters, calculated as the mean proportion of membership values for individuals within that population provided by the TESS analysis. Colours within pie charts correspond to the genetic clusters in Figure 3.

markers. Allele frequency distributions were assessed via the qualitative mode shift test and statistical significance was tested using Wilcoxon signed-rank tests.

Genetic structure. Genetic structure was investigated using the Bayesian assignment approach used in the TESS version 2.3 software (Chen et al., 2007). An optimal number of clusters $(K)$ were determined across the species range and the fraction of an individual's genome $\left(q_{\mathrm{i}}\right)$ originating in each of the $K$ clusters was estimated for all individuals. The program incorporates spatial dependencies using a spatial interaction parameter $(\psi)$ to weight the degree of spatial autocorrelation incorporated into spatial networks at the cluster membership level. We provided unique spatial coordinates for each plant sampled and, because of the irregular sampling design, incorporated weights $(\psi=0.60)$ that depend on geographic distance among sampling sites using the compute geographic distance option. Voronoï tessellations were used to create polygonal neighbourhoods for sampled populations with adjacent populations connected via Delaunay triangulation. Given the species limited geographic range, we allowed far samples to be connected and did not remove any external or internal edges of the tessellation. We used the conditional auto-regressive Gaussian admixture model for analysis with a burn in of 10000 runs and a further 50000 Markov chain repetitions and 10 iterations of each run from $K=2$ to $K=10$. A value of $K=10$ was chosen as an unlikely arbitrary upper limit of the number of possible clusters in order to minimise unnecessary runs at high values of $K$. The mean deviance information criteria (DIC) for each $K$ were plotted against $K$ and the optimal $K$ determined as that at which deviance information criteria levelled out considerably. We obtained values of the proportion of membership of each individual to given clusters at the optimal $K\left(q_{i}\right)$, and a bar plot illustrating these values. We obtained a map illustrating the assignment of polygons across the spatial network to each of the five optimal clusters. The proportion of membership of individuals in each population to each of the five optimal clusters was also calculated.

Genetic differentiation. To eliminate bias because of very small population sizes, three populations with eight plants or less (MASC, MDSE, WN) and the single plant from WS were excluded from $F_{\mathrm{ST}^{-}}$-based analysis of population differentiation. The degree of genetic differentiation was assessed using global values of genetic differentiation obtained for: the species overall where the population was all individuals within a sample site, the four regions where the population was all individuals within a region, and for the two multi population regions, Jasper Hill and Mungada/Windaning Ridge, where the population was all individuals within a sample site within that region. Pairwise values were also obtained among populations. Values were based on allele identity using the intra-class kinship coefficient $F_{\mathrm{ST}}$. Significance was tested using $P$-values obtained for 10000 permutations of individual genotypes using the SPAGeDi version 1.3 program (Hardy and Vekemans, 2002).

Mantel tests were used to test for isolation by distance, which is a correlation between population differentiation and spatial distance, using matrices of $F_{\mathrm{ST}}\left(F_{\mathrm{ST}} /\left(1-F_{\mathrm{ST}}\right)\right)$ and the log of the geographic distances. Analysis was conducted for the species overall, where the population was all individuals within a sample site, and for the two multi-population regions, where the population was all individuals within a sample site within that region. Significance of the correlation between population differentiation and spatial distance was tested using $P$-values for 10000 permutations of sample sites and conducted using SPAGeDi.

To test for a phylogeographic signal, differentiation in microsatellite allele sizes $\left(R_{\mathrm{ST}}\right)$ was assessed at the species level where the population was all individuals at a sampled site, at a regional level where the population was all individuals within a region, and pairwise among populations. Analyses were conducted using SPAGeDi and are insightful under a model of stepwise mutation for microsatellite loci (Slatkin, 1995). Allele identity data were first converted to a format representing the microsatellite repeat number. Significance of the slopes of $R_{\mathrm{ST}} /\left(1-R_{\mathrm{ST}}\right)$ over logarithmic geographic distances was tested using 10000 permutations of allele sizes among alleles within loci following Pons and Petit (1996) and Hardy et al. (2003). This test allowed for the assessment of whether mutations at microsatellite loci contributed to differentiation among the most spatially distant populations. 
$F_{\mathrm{ST}}$ and $R_{\mathrm{ST}}$ values were converted to the number of migrants $(\mathrm{Nm})$ following Slatkin's island model (Slatkin, 1995), and Nm was also estimated independently of $F_{\mathrm{ST}}$ based on private alleles with correction for sample size, following Barton and Slatkin (1986). Analysis was conducted with the GENEPOP program.

\section{RESULTS}

\section{Utility of loci}

After adjusting for multiple comparisons $(n=495)$, significant departure from Hardy-Weinberg equilibrium $(P<0.05)$ in the form of heterozygote deficiency was observed at locus B003 at JHB, JHBS and Blue Hill, locus B109 at MA2 and MA4, and at loci A124, A129, B001, B107, B109, D008, D010, D012 and D116 at Blue Hill. Heterozygote excess was observed for the locus AwC001 at JHBS, JHD, JHE, MA1, MA3, MA4, MA5, MA6, WA1, WA3, WD and Blue Hill. After adjusting for multiple comparisons $(n=3465)$, significant linkage disequilibrium $(P<0.01)$ was detected for seven locus pairs at Blue Hill only. Null alleles were present at frequencies of $<0.10$ in $81 \%$ of 495 locus/population combinations. Lack of linkage disequilibrium in undisturbed populations and generally low frequencies of null alleles leads us to conclude that observed departures from HardyWeinberg equilibrium are because of occasional departures from random mating and that the loci are generally suitable for the analysis of genetic diversity and spatial genetic structure in A. woodmaniorum.

\section{Genetic diversity}

Fourteen of the 15 microsatellite loci were polymorphic at all sample sites of A. woodmaniorum. A total of 199 alleles were detected across 15 loci. The number of alleles present ranged from a maximum of 171 across Mungada/Windaning Ridge to a minimum of 62 alleles at Terapod. The mean number of alleles per locus, number of effective alleles and level of expected heterozygosity were greatest across Mungada/Windaning Ridge and lowest at Terapod. However, following rarefaction, there was no difference in mean number of alleles per locus and number of private alleles per locus across the four regions (Table 1). Levels of observed heterozygosity were similar and marginally lower than expected heterozygosity in all regions. Unique alleles were detected at 25 of the 33 sample sites; 10 alleles at Jasper Hill, 41 alleles at Mungada/Windaning Ridge, 12 alleles at Blue Hill and 1 at Terapod. Fixation indices varied but most populations (Supplementary Table S1) and regions (Table 1) showed little evidence of inbreeding. There was no significant correlation between the number of alleles $\left(P=0.333, R^{2}=0.043\right)$, number of private alleles $\left(P=0.340, R^{2}=0.041\right)$, or fixation index $\left(P=0.312, R^{2}=0.046\right)$ and population isolation, or between the number of alleles $(P=0.281$, $\left.R^{2}=0.053\right)$, number of private alleles $\left(P=0.650, R^{2}=0.010\right)$, or fixation index $\left(P=0.300, R^{2}=0.049\right)$ and population size.
Hierarchically, based on allelic identity, $5 \%$ of genetic diversity in A. woodmaniorum occurs among regions, $6 \%$ among populations, $20 \%$ within populations and $69 \%$ within individuals. There was no evidence of recent population size reductions in A. woodmaniorum. BOTTLENECK analysis indicated a normal L-shaped distribution of allele sizes and no significant deficit of heterozygosity given the number of alleles present at any population.

\section{Genetic structure}

Determination of deviance information criteria values for different numbers of clusters using TESS analysis indicated the optimal number of clusters as five (Supplementary Table S2). Many plants had shared ancestry among more than one cluster reflecting a degree of genetic connectivity among populations. The proportion of membership of each sampled individual is provided as Supplementary Material (Supplementary Table S3) and illustrated in Figure 3. The distribution of the five clusters, in terms of the network constructed across the landscape, is illustrated in Supplementary Figure S1. This indicates the most likely overall assignment to a single genetic cluster for populations that occur in each of the constructed polygons across the species range.

Proportional assignment of populations to each of the five clusters is illustrated in Figure 1. Plants from Jasper Hill had the greatest mean proportion of membership to the red cluster $\left(Q_{\mathrm{i}}=0.77\right)$ and showed a degree of association with a second green cluster $\left(Q_{i}=0.21\right)$. Plants from Mungada/Windaning Ridge clustered according to which section of the ridge they occurred on. Plants on Mungada Ridge had the majority proportion of membership to the green cluster $\left(Q_{i}=0.57\right)$ and a smaller proportion to a third yellow cluster $\left(Q_{i}=0.24\right)$. Plants on Windaning Ridge had a large mean proportion of membership to the yellow cluster $\left(Q_{i}=0.75\right)$ and a smaller proportion to the green cluster $\left(Q_{i}=0.22\right)$. Plants at Terapod had the majority proportion of membership to the green cluster $\left(Q_{i}=0.54\right)$ and the red cluster $\left(Q_{i}=0.25\right)$. Most individuals from the Blue Hill region showed a high proportion of membership to a fourth blue cluster $\left(Q_{\mathrm{i}}=0.60\right)$ or a fifth purple cluster $\left(Q_{\mathrm{i}}=0.34\right)$. Greater proportion of membership of plants at Terapod and Jasper Hill to the green cluster $\left(Q_{\mathrm{i}}=0.25\right.$ and 0.21$)$ compared with the proportion of membership of plants on Mungada/ Windaning Ridge to the red cluster $\left(Q_{i}=0.09\right.$, Supplementary Table S3) suggests a greater level of allelic dispersal from the south to the north. Proportion of membership values also suggest dispersal of alleles to the east from Blue Hills $\left(Q_{i}\right.$ for the green and yellow clusters combined $=0.05$ ) to Mungada/Windaning Ridge $\left(Q_{\mathrm{i}}\right.$ for the blue and purple clusters combined $=0.11$, Supplementary Table S3).

Table 1 Microsatellite diversity for four regions of Acacia woodmaniorum and for the species overall

\begin{tabular}{|c|c|c|c|c|c|c|c|c|c|c|c|}
\hline Sample region & $\begin{array}{l}\text { Number } \\
\text { of plants }\end{array}$ & $\begin{array}{c}\text { Isolation } \\
\text { (m) }\end{array}$ & $\mathrm{N}$ & $A$ & $\mathrm{Ne}$ & $\mathrm{P}$ & $\mathrm{H}_{e}$ & $\mathrm{H}_{0}$ & $\mathrm{~F}_{/ S}$ & $A_{r}$ & $\mathrm{P}_{r}$ \\
\hline Jasper Hill & 3108 & & 138 & $7.933(1.071)$ & $2.984(0.414)$ & 100.00 & $0.588(0.044)$ & $0.522(0.054)$ & - & 2.59 & 0.06 \\
\hline Mungada/Windaning Ridge & 22019 & & 280 & $11.40(1.264)$ & $3.784(0.660)$ & 100 & $0.627(0.051)$ & $0.521(0.049)$ & - & 2.78 & 0.09 \\
\hline Blue Hill & 145 & 1870 & 145 & $8.533(1.162)$ & $3.102(0.574)$ & 100 & $0.573(0.051)$ & $0.509(.061)$ & $0.106(0.080)$ & 2.77 & 0.14 \\
\hline Terapod & 10 & 700 & 10 & $4.133(0.496)$ & $2.806(0.303)$ & 93.33 & $0.564(0.057)$ & $0.533(0.067)$ & $0.043(0.076)$ & 2.83 & 0.03 \\
\hline Species (total or mean and s.e.) & 25282 & & 573 & $4.331(0.111)$ & $2.677(0.064)$ & 95.15 & $0.531(0.010)$ & $0.529(0.013)$ & $-0.008(0.018)$ & 2.73 & 0.08 \\
\hline
\end{tabular}

The number of plants in the region, degree of isolation, number of plants sampled $(N)$ and genetic diversity parameters including the mean number of alleles per locus ( $A$ ), the number of effective alleles $\left(N_{\mathrm{e}}\right)$, the proportion of polymorphic loci $(P)$, expected $\left(H_{\mathrm{e}}\right)$ and observed $\left(H_{0}\right)$ heterozygosity, the fixation index $\left(F_{\mathrm{IS}}\right)$, the number of alleles per locus after rarefaction $\left(A_{\mathrm{r}}\right)$ and the number of private alleles after rarefaction $\left(P_{r}\right)$ are shown. Values in parentheses are standard errors. 


\section{Genetic differentiation}

Global genetic differentiation $\left(F_{\mathrm{ST}}\right)$ among sample sites of A. woodmaniorum was moderate (Table 2 ) and significantly greater than the mean permuted value across the range, indicating the presence of significant genetic structure among populations $(P=0.000)$. Global genetic differentiation among regions was lower (Table 2) but still significant $(P=0.000)$. Differentiation among populations was significant $(P=0.000)$ within both of the multipopulation regions Mungada/Windaning Ridge and Jasper Hill (Table 2). Pairwise population estimates and their significance values are provided in the Supplementary Material (Supplementary Table S4).

The slope of the regression of pairwise population values of $F_{\mathrm{ST}} /\left(1-F_{\mathrm{ST}}\right)$ was significant for logarithmic geographic distances $\left(R^{2}=0.267, P=0.000\right)$, indicating an effect of isolation by distance across the species range (Figure 2). A quadratic relationship was detected. Slopes were also significant showing a linear relationship at Jasper Hill $\left(R^{2}=0.339\right.$, slope $\left.=0.046, P=0.001\right)$ and at Mungada/ Windaning Ridge $\left(R^{2}=0.116\right.$, slope $\left.=0.016, P=0.000\right)$.

Table 2 Mean values of pairwise genetic differentiation among 29 sampled sites, among 4 regions and within 2 multi-population regions of

\section{A. woodmaniorum}

\begin{tabular}{lcccc}
\hline Sites, regions or species & $\mathrm{F}_{S T}$ & $\mathrm{R}_{S T}$ & $\mathrm{pR}$ & $\mathrm{P}$ \\
\hline Global & 0.097 & 0.127 & 0.094 & 0.039 \\
Regional & 0.069 & 0.112 & 0.065 & 0.017 \\
Jasper Hill & 0.094 & 0.108 & 0.095 & 0.290 \\
Mungada/Windaning Ridge & 0.049 & 0.013 & 0.024 & 0.840
\end{tabular}

Abbreviations: $F_{\mathrm{ST}}$, Weir and Cockerham's intra-class kinship coefficient; $P, P$-value after 10000 permutations of allele sizes; $R_{\mathrm{ST}}$, correlation of allele sizes; $\mathrm{pR}$ ST, correlation of allele sizes after 10000 permutations of allele sizes.

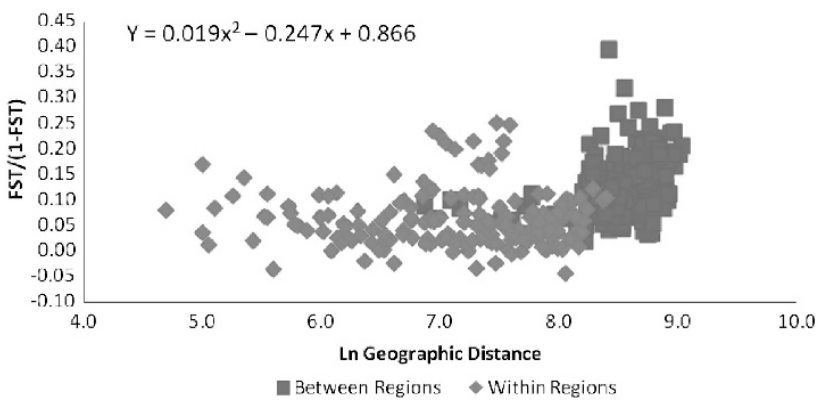

Figure 2 Mantel test of correlation of genetic distance with geographic distance for populations of $A$. woodmaniorum. Pairwise values between populations within and between different regions are graphed.

Table 3 Pairwise genetic differentiation for four regions of Acacia woodmaniorum

\begin{tabular}{lcccc}
\hline & Jasper Hill & $\begin{array}{c}\text { Mungadal } \\
\text { Windaning Ridge }\end{array}$ & $\begin{array}{c}\text { Blue } \\
\text { Hill }\end{array}$ & Terapod \\
\hline Jasper Hill & - & $0.129^{a}$ & $0.187^{a}$ & 0.109 \\
Mungada/Windaning Ridge & 0.050 & - & 0.045 & 0.094 \\
Blue Hill & 0.111 & 0.062 & - & 0.119 \\
Terapod & 0.054 & 0.048 & 0.097 & -
\end{tabular}

$F_{\mathrm{ST}}$ values are below the diagonal and $R_{\mathrm{ST}}$ values are above the diagonal.

avalues of $R_{\mathrm{ST}}$ that are significantly greater than $F_{\mathrm{ST}}$ at the $5 \%$ level after 10000 permutations of allele sizes.
Global $R_{\mathrm{ST}}$ was significantly greater than the permuted value $\left(R_{\mathrm{ST}}=0.127, \mathrm{pR}_{\mathrm{ST}}=0.094, P=0.039\right)$, indicating a phylogeographic signal in microsatellite loci among populations. Pairwise $R_{\mathrm{ST}} /\left(1-R_{\mathrm{ST}}\right)$ values were significantly correlated with logarithmic geographic distance $\left(R^{2}=0.156\right.$, slope $\left.=0.071, P=0.005\right)$ at the population level. Global $R_{\mathrm{ST}}$ was also significant at the regional scale $\left(R_{\mathrm{ST}}=0.112\right.$, $\left.\mathrm{pR}_{\mathrm{ST}}=0.000, P=0.000\right)$ but pairwise values were not significantly correlated with logarithmic geographic distance $\left(R^{2}=0.210\right.$, slope $=0.073, P=0.122$ ). Pairwise regional estimates of genetic differentiation based on allele sizes were greater than those based on allelic identity, except for the Blue Hill and Mungada/Windaning Ridge comparison (Table 3). Pairwise regional estimates of differentiation based on allele sizes were significant between Jasper Hill and both the Mungada/Windaning Ridge and Blue Hill regions (Table 3).

Moderate levels of genetic differentiation in A. woodmaniorum are reflected in $F_{\mathrm{ST}}$-derived estimates of the number of migrants per generation; $\mathrm{Nm}=3.37$ among four regions. The number of migrants among populations was moderate at Jasper Hill $(\mathrm{Nm}=2.41)$ and greater at Mungada/Windaning Ridge $(\mathrm{Nm}=4.85) . \quad R_{\mathrm{ST}}$-derived estimates were lower; $\mathrm{Nm}=1.98$ among four regions, $\mathrm{Nm}=2.06$ within Jasper Hill and $\mathrm{Nm}=4.65$ at Mungada/Windaning Ridge indicating that the mutation rate is marked relative to migration. Estimates of $\mathrm{Nm}$ based on private alleles were higher than those derived from F-statistics ( $\mathrm{Nm}=6.19$ among four regions), but showed a different pattern within regions, being lower across the continuous range $(\mathrm{Nm}=2.14)$ and higher at Jasper Hill $(\mathrm{Nm}=2.90)$.

\section{DISCUSSION}

Studies of rare plant species with geographically restricted and disjunct population distributions arising from historical rarity and habitat specificity can provide valuable insights into understanding levels of connectivity and how connectivity impacts genetic structuring within species. They can also assist in better understanding the maintenance of genetic diversity in relatively small isolated populations. Here we detected a signal of phylogeographic and genetic structure, and of isolation by distance among populations of A. woodmaniorum, an endemic species of the ancient BIF inselbergs of WA's Yilgarn Craton. Despite being relatively small and located on disjunct outcrops, low-to-moderate levels of genetic differentiation were maintained among populations and moderate levels of genetic diversity were maintained within populations.

The limited genetic differentiation among populations and maintenance of moderate levels of genetic diversity in A. woodmaniorum indicate that levels of gene flow are more than sufficient to spread advantageous alleles among populations over long periods of evolutionary time, effectively maintaining 'adaptive connectivity' across the limited range (Lowe and Allendorf, 2010). Estimates of the fixation index and levels of genetic diversity indicate that gene flow in the order of two to five migrants per generation is also sufficient to produce 'inbreeding connectivity'. These results support the view that this level of gene flow, although lower than the mutation rate, is sufficient to largely counteract deleterious genetic effects of local inbreeding and of random genetic drift in even the most isolated and smallest populations (Rieseberg and Burke, 2001; Lowe and Allendorf, 2010).

Signals of phylogeographic and genetic structure across the species range indicate that gene flow is insufficient to completely counter changes in allele frequencies because of mutation and random genetic drift, or to maintain complete 'drift connectivity' among populations on disjunct BIF outcrops. The quadratic relationship between genetic differentiation and geographic distance indicates that limitations to 


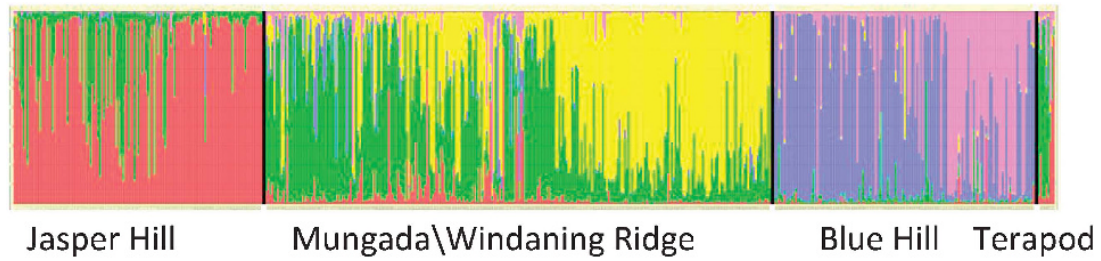

Figure 3 Assignment of individuals of $A$. woodmaniorum to each of five clusters detected using TESS. Each individual is represented as a vertical line partitioned into coloured segments whose length is proportional to the individual coefficients of membership in each of the five clusters. Red, cluster 1; green, cluster 2; yellow, cluster 3; blue, cluster 4; purple, cluster 5. Individuals are grouped by sample site and region in the order listed in Supplementary Table S1.

gene flow become significant at distances of around $740 \mathrm{~m}$. The results indicate greater levels of gene flow are likely required to bring about 'drift connectivity' in this species, supporting Lowe and Allendorf's (2010) suggestion that somewhere in the order of $\mathrm{Nm} \geqslant 10$ migrants per generation may be required to produce similar allele frequencies in all populations and panmictic population structure.

Further evidence that the size and level of disjunction among the specialised BIF habitat influences dispersal and genetic connectivity is suggested by the greater levels of genetic differentiation and stronger affect of isolation by distance observed among populations at Jasper Hill than at Mungada/Windaning Ridge. Despite populations at Jasper Hill occurring over a shorter geographic distance $(2 \mathrm{~km}$ compared with $5.5 \mathrm{~km}$ at Mungada/Windaning Ridge), the ironstone habitat and associated populations of A. woodmaniorum are more disjunct and smaller at Jasper Hill than across the relatively continuous habitat and large population on Mungada/Windaning Ridge. The degree of genetic structure at Jasper Hill may be influenced by the effects of genetic drift under a scenario of limited pollen production and dispersal among populations of smaller effective size

Despite the suitability of inselberg habitats for studies assessing genetic connectivity and the occurrence of inselberg habitat around the world, detailed studies of endemic inselberg flora are limited. Species occurring on granite outcrops in WA have shown higher levels of genetic differentiation than observed in A. woodmaniorum, for example, Eucalyptus caesia (Byrne and Hopper, 2008) and Verticordia staminosa subspecies cylindacea (Yates et al., 2007). Populations of these species are distributed over wider geographical ranges and have greater levels of geographic isolation however. South American populations of the Neotropical bromeliads Alcantarea imperialis and Pitcairnia geyskesii in (Sarthou et al., 2001; Barbara et al., 2007) are also distributed over wider geographical ranges with greater geographic isolation and display high levels of genetic differentiation. Levels of genetic differentiation among populations of A. woodmaniorum are similar to those of Alcantarea geniculta, which has a more similar restricted geographic range (Barbara et al., 2008). The degree of genetic connectivity among disjunct populations of both $A$. woodmaniorum and $A$. geniculata is likely to be a result of successful pollen and/or seed dispersal over limited geographic ranges, although high levels of genetic differentiation have also been observed among populations of species with even more geographically restricted ranges, for example, the Western Australian BIF endemic Tetratheca paynterae subspecies paynterae (Butcher et al., 2009).

Overall, historical limitations to dispersal of seed and/or pollen in A. woodmaniorum do appear to be weak despite the disjunct ironstone habitat and population distribution, and long distance dispersal (over several $\mathrm{km}$ ) may be routine for this species. Passerine birds that disperse seed in some Acacia are unlikely to do so for A. woodmaniorum as it does not retain seed on the plant and lacks bird attracting extrafloral nectaries and brightly coloured arillate diapsore appendages (Davidson and Morton, 1984). The majority of Australian Acacia have traditionally been thought to be dispersed only short distances (metres) by ants (Davidson and Morton, 1984; Hughes and Westoby, 1992; Gómez and Espadaler, 1998), although the frequency of long distance dispersal events may be greatly underestimated. One of the primary dispersers, the widespread, dominant meat ant species, Iridomyrmex viridiaeneus, is capable of dispersing Acacia seed $180 \mathrm{~m}$ from the parental tree (Whitney, 2002). Highly abundant and mobile animals including large birds such as emus (Dromaius novahollandiae) and mammals such as western grey kangaroos (Macropus fuliginosus) that ingest and disperse Acacia seed may also act as important long distance (tens of kilometres), (Calviño-Cancela et al., 2006, 2008) dispersers.

Infrequent but relatively long distance pollen dispersal in A. woodmaniorum may also be occasionally expected. Generalist insects including native and introduced bees are known to routinely fly distances of several kilometres, especially among fragmented habitat (Dick, 2001; Jha and Dick, 2010; Hagler et al., 2011) and may directly facilitate pollen dispersal when traversing intervening unsuitable habitat among populations. Pollen dispersal over a distance of $1.6 \mathrm{~km}$ has also been recorded previously for A. saligna, a common widespread species of the more mesic areas of south west WA, using direct paternity analysis methods (Millar et al., 2008, 2012).

Interestingly, Bayesian analysis provides some evidence that wind direction may influence gene flow in A. woodmaniorum pollen. Genetic structure of populations across the landscape suggests slightly greater gene flow from south to north, in association with the prevailing winds at the study site during flowering. Mean proportion of membership values suggest slightly greater gene flow from Windaning Ridge into Mungada Ridge, and from Mungada Ridge to Terapod and to Jasper Hill, than vice versa (see Figure 3, Supplementary Figure S1 and Supplementary Table S3). A. woodmaniorum occupies the highest points in the landscape and it is possible winds may facilitate a degree of long distance dispersal of small generalist insects carrying pollen loads. Given this and the relative geographic continuity of populations over this region, the degree of genetic divergence among sample sites located on Mungada Ridge and those located on Windaning Ridge was unexpected.

Levels of diversity in A. woodmaniorum are not particularly low and are also comparable to those of the widespread A. saligna (Millar and Byrne, 2012). Although the genus Acacia is very large, the A. saligna study is currently the only one using a similar suite of microsatellite markers that can be used to realistically compare levels of genetic diversity. Although low levels of neutral genetic diversity might be expected in small disjunct populations of insect pollinated inselberg endemics, levels of genetic diversity in A. woodmaniorum suggest this is not always the case. 
Given the rarity, high degree of habitat specificity and lack of evidence of recent genetic bottlenecks, levels of genetic diversity in A. woodmaniorum are unlikely to be a result of the recent fragmentation of a more widespread congener. As none of the proposed closest relatives of A. woodmaniorum are sympatric or parapatric, levels of genetic diversity are also unlikely to be increased as a result of recent hybridisation. Given likely physiological adaptation to the skeletal soils of the historically stable BIF habitat (Poot and Lambers, 2007), A. woodmaniorum is likely to have evolved over long time frames. Furthermore, although effective population sizes have not been determined, when viewed in combination with the phylogeographic and genetic structure and pattern of isolation by distance across the species range, relatively high levels of diversity support the view that A. woodmaniorum has persisted in populations with large effective size in the current distribution over long time periods.

\section{CONCLUSION}

Significant phylogeographic and genetic structure across the species range suggests historical persistence of $A$. woodmaniorum populations in their current distributions. The greatest genetic differentiation occurred between the two main regions of the species distribution, although degree of disjunction and size of populations may have a stronger effect on genetic connectivity than does geographic distance alone. Genetic structure indicates genetic connectivity is insufficient to produce panmictic allele frequencies across the species range and there is some affect of random genetic drift on geographically disjunct small populations. Despite this, seed and/or pollen dispersal appears to extend well beyond adjacent populations. Gene flow in the order of more than two or three migrants per generation is sufficient to provide 'adaptive connectivity' and to largely counter any negative genetic effects of inbreeding because of mate limitation or random genetic drift, and to maintain levels of diversity in even the most disjunct, smallest populations. Correlation between the direction of allele dispersal and prevailing winds during flowering may provide the first evidence of a degree of wind facilitated dispersal of Acacia pollen loaded insects.

Studies such as this reveal the influence of genetic connectivity in ensuring persistence of historically rare species in specialised habitats over long time frames. This information will be valuable in informing the likely effects of future anthropogenic disturbance, such as the impact of the loss of populations on species genetic diversity, and in practical applications such as the placement of restored populations in the landscape. Similar studies are desirable for biodiversity conservation and management of other rare, habitat-specific species in many landscapes around the world.

\section{DATA ARCHIVING}

Data deposited in the Dryad repository: doi:10.5061/dryad.1p145.

\section{CONFLICT OF INTEREST}

The authors declare no conflict of interest.

\section{ACKNOWLEDGEMENTS}

This research was conducted with financial support from Karara Mining Ltd. We thank Greg Woodman for provision of GIS data, Niall Sheehy and Heidi Nistelberger for assistance in the field, Shelley McArthur for assistance in the laboratory and reviewers and journal editors for constructive comment on the draft manuscript.
Anand R, Paine M (2002). Regolith geology of the Yilgarn Craton, Western Australia: implications for exploration. Aust J Earth Sci 49: 3-162.

Barbara T, Lexer C, Martinelli G, Mayo J, Fay M, Heuertz M (2008). Within-population spatial genetic structure in four naturally fragmented species of a neotropical inselberg radiation, Alcantarea imperialis, A. geniculata, A. glaziouana and A. regina (Bromeliaceae). Heredity 101: 285-296.

Barbara T, Martinelli G, Fay M, Mayo J, Lexer C (2007). Population differentiation and species cohesion in two closely related plants adapted to neotropical high-altitude 'inselbergs', Alcantarea imperialis and Alcantarea geniculata (Bromeliaceae). Mol Ecol 16: 1981-1992.

Barton NH, Slatkin M (1986). A quasi-equilibrium theory of the distribution of rare alleles in a sub-divided population. Heredity 56: 409-415.

Beard JS (1976). Murchison, 1:1,000,000 Vegetation Series: The Vegetation of the Murchison Region. University of Western Australia Press: Perth.

Butcher P, McNee S, Krauss S (2009). Genetic impacts of habitat loss on the rare ironstone endemic Tetratheca paynterae subsp paynterae.. Conserv Genet 10: $1735-1746$.

Byrne M, Hopper S (2008). Granite outcrops as ancient islands in old landscapes: evidence from the phylogeography and population genetics of Eucalyptus caesia (Myrtaceae) in Western Australia. Biol J Linn Soc 93: 177-188.

Calviño-Cancela M, Dunn R, Evan Etten E, Lamont B (2006). Emus as non standard seed dispersers and their potential for long-distance dispersal. Ecography 29: 632-640.

Calviño-Cancela M, He T, Lamont B (2008). Distribution of myrmecochorous species over the landscape and their potential long-distance dispersal by emus and kangaroos. Divers Distrib 14: 11-17.

Chen C, Durand E, Forbes F, Francois O (2007). Bayesian clustering algorithms ascertaining spatial population structure: a new computer program and a comparison study. Mol Ecol Notes 7: 747-756.

Coates DJ (2000). Defining conservation units in a rich and fragmented flora: implications for the management of genetic resources and evolutionary processes in south-west Australian plants. Aust J Bot 48: 329-339.

Davidson D, Morton S (1984). Dispersal adaptations of some Acacia species in the Australian arid zone. Ecology 65: 1038-1051.

Dick C (2001). Genetic rescue of remnant tropical trees by an alien pollinator. Proc $R$ Soc Lond B Biol Sci 268: 2391-2396

Ellstrand N (1992). Gene flow among seed plant populations. New For 6: 241-246.

Gibson N, Yates C (2010). Plant communities of the ironstone ranges of south western Australia: Hotspots for plant diversity and mineral deposits. Biodivers Conserv 19: 3951-3962.

Gómez C, Espadaler X (1998). Myrmecochorous dispersal distances: a world survey. J Biogeogr 25: 573-580.

Hagler JR, Mueller S, Teuber LR, Machtley SA, Van Deynze A (2011). Foraging range of honey bees, Apis mellifera, in alfalfa seed production fields. J Insect Sci 11: 144

Hardy OJ, Charbonnel N, Frevilee H. Heuertz M (2003). Microsatellite allele sizes: a simple test to assess their significance on genetic differentiation. Genetics 163: 1467-1482.

Hardy OJ, Vekemans X (2002). SPAGeDi: a versatile computer program to analyse spatial genetic structure at the individual or population levels. Mol Ecol Notes 2: 618-620.

Hopper S (2009). OCBIL theory: towards an integrated understanding of the evolution, ecology and conservation of biodiversity on old, climatically buffered infertile landscapes. Plant Soil 322: 49-86

Hopper S, Gioia P (2004). The southwest Australian floristic region: evolution and conservation of a global hot spot of biodiversity. Annu Rev Ecol Evol Syst 35: 623-650.

Hopper S, Harvey M, Chappill J, Main A, Main B (1996). The Western Australian biota as Gondwanan heritage - a review. In: Hopper S, Chappill J, Harvey M, George A (eds) Gondwanan Heritage - Past Present and Future of the Western Australian Biota. Surrey Beaty and Sons: Chipping Norton, NSW, Australia.

Hughes L, Westoby M (1992). Fate of seeds adapted for dispersal by ants in Australian schlerophyll vegetation. Ecology 73: 1285-1299.

Jha S, Dick CW (2010). Native bees mediate long-distance pollen dispersal in a shade coffee landscape mosaic. Proc Natl Acad Sci USA 107: 1370-13760-13764.

Kalinowski S (2005). HP-RARE 1.0: a computer program for performing rarefaction on measures of allelic richness. Mol Ecol Notes 5: 187-189.

Lowe W, Allendorf FW (2010). What can genetics tell us about population connectivity? $\mathrm{Mol}$ Ecol 19: 3038-3051.

Markey A, Dillon S (2008). Flora and vegetation of the banded iron formations of the Yilgarn Craton: the central Tallering Land System. Conserv Sci West Aust 7: 121-149.

Maslin B, Buscumb C (2007). Two new Acacia species (Leguminosae: Mimosoideae) from banded ironstone ranges in the Midwest region. Nuytsia 17: 263-272.

Millar M, Byrne M (2013). Cryptic divergent lineages of Pultenaea pauciflora M.B. Scot (Fabacaea:Mirbelieae) exhibit different evolutionary history. Biol J Linn Soc 108 : $871-881$.

Millar MA (2009). Characterisation of microsatellite DNA markers for the rare Acacia woodmaniorum (Leguminosae: Mimosaceae). Conserv Genet Resour 1: 441-445.

Millar MA, Byrne M (2012). Biogeographic origins and reproductive mode of naturalised populations of Acacia saligna. Aust J Bot 60: 383-395.

Millar MA, Byrne M, Nuberg I, Sedgley M (2008). High outcrossing and random pollen dispersal in a planted stand of Acacia saligna subsp. saligna revealed by paternity analysis using microsatellites. Tree Genet Genomes 4: 367-377.

Millar MA, Byrne M, Nuberg IK, Sedgley M (2012). High levels of genetic contamination in remnant populations of Acacia saligna from a genetically divergent planted stand. Restor Ecol 20: 260-267. 
Myers N, Mittermeier R, Mittermeier C, da Fonseca G, Kent J (2000). Biodiversity hotspots for conservation priorities. Nature 403: 853-858.

Peakall R, Smouse P (2006). GenAIEx 6: genetic analysis in Excel. Population genetic software for teaching and research. Mol Ecol Notes 6: 288-295.

Piry S, Luikart G, Cournet J (1999). Bottleneck: a computer program for detecting recent reductions in the effective population size using allele frequency data. J Hered $\mathbf{9 0}$ : 502-503.

Pons O, Petit R (1996). Measuring and testing genetic differentiation with ordered versus unordered alleles. Genetics 144: 1237-1245.

Poot P, Lambers H (2007). Shallow-soil endemics: adaptive advantaages and constraints of a specialised root-system morphology. New Phytol 178: 371-381.

Porembski S (2007). Tropical inselbergs: habitat types, adaptive strategies and diversity patterns. Revista Brasil Botany 30: 579-586.

Porembski S, Barthlott W (2000). Inselbergs. Biotic Diversity of Isolated Rock Outcrops in Tropical and Temperate Regions. Springer Verlag: Berlin, Heidelberg, New York.

Raymond M, Rousset F (1995). GENEPOP (version 3.4): population genetics software for exact test and ecumenicism. J Hered 86: 248-249.
Rieseberg LH, Burke J (2001). The biological reality of species: gene flow, selection, and collective evolution. Taxon 50: 47-67.

Sarthou C, Samadi S, Boisselier-Dubayle M (2001). Genetic structure of the saxicole Pitcairnia geyskesii (Bromelaceae) on inselbergs in French Guiana. Am J Bot 88: 861-868.

Slatkin M (1987). Gene flow and the geographic structure of natural populations. Science 236: 787-792.

Slatkin M (1995). A measure of population subdivision based on microsatellite allele frequencies. Genetics 139: 457-462.

Stone GN, Raine NE, Prescott M, Willmer PG (2003). Pollination ecology of acacias (Fabaceae, Mimosoideae). Aust Syst Bot 16: 103-118.

Whitney K (2002). Dispersal for distance? Acacia ligulata seeds and meat ants Iridomymex viridiaeneus. Austral Ecol 27: 589-595.

Wright S (1951). The genetical structure of natural populations. Annals of Eugenics 15 : 323-354.

Yates CJ, Ladd PG, Coates DJ, McArthur S (2007). Hierarchies of cause: Understanding rarity in an endemic shrub Verticordia staminosa (Myrtaceae) with a highly restricted distribution. Aust J Bot 55: 194-205.

Supplementary Information accompanies this paper on Heredity website (http://www.nature.com/hdy) 